\title{
Approaches in cooling of resistive coil- based low-field Magnetic Resonance Imaging (MRI) systems for application in low resource settings
}

\author{
Faith Natukunda ${ }^{1 *}$ (D), Theodora M. Twongyirwe ${ }^{2}$, Steven J. Schiff ${ }^{3}$ and Johnes Obungoloch ${ }^{1}$
}

\begin{abstract}
Magnetic Resonance Imaging (MRI), a non-invasive method for the diagnosis of diverse health conditions has experienced growing popularity over other imaging modalities like ultrasound and Computer Tomography. Initially, proof-of-concept and earlier MRI systems were based on resistive and permanent magnet technology. However, superconducting magnets have long held monopoly of the market for MRI systems with their high-field (HF) strength capability, although they present high construction, installation, and siting requirements. Such stringent prerequisites restrict their availability and use in low-middle income countries. Resistive coil-based magnet, albeit low-field (LF) in capacity, represent a plausible boost for the availability and use of MRI systems in resource constrained settings. These systems are characterized by low costs coupled with substantial image quality for diagnosis of some conditions such as hydrocephalus common is such regions. However, the nature of resistive coils causes them to heat up during operation, thus necessitating a dedicated cooling system to improve image quality and enhance system longevity. This paper explores a range of cooling methods as have been applied to resistive magnets, citing their pros and cons and areas for improvement.
\end{abstract}

Keywords: Low-field MRI, Resistive, Cooling, Temperature, Power dissipation

\section{Background}

The principles of Nuclear Magnetic Resonance have been applied long before the discovery of Magnetic Resonance Imaging (MRI). However, it was not until 1973, when Lauterbur [1] demonstrated image construction, that a rapid growth in Magnetic Resonance Imaging commenced. Magnetic resonance imaging has been of outstanding impact in the healthcare industry. As a noninvasive method, it has gained popularity over $x$-ray computer tomography in the diagnosis of the brain, spine, nervous and cardiovascular systems on account of

\footnotetext{
* Correspondence: fnatukunda@must.ac.ug

'Department of Biomedical Engineering, Mbarara University of Science and Technology, Mbarara, Uganda

Full list of author information is available at the end of the article
}

its notable image quality especially for soft tissue imaging. MRI systems generally employ resistive, permanent, or superconducting magnets to produce a homogeneous magnetic field that uniformly polarizes the nuclear magnetic spins of the subject.

In 1980, the first commercial clinical MRI was made by Fonar. It was constructed using a heavy permanent magnet [2]. Permanent [3-5] and resistive [6, 7] magnets were the precursor technologies for the early commercial MRI scanners before superconductive magnets were discovered. Resistive magnets, although lighter than permanent magnets, exhibited power requirements as high as $40 \mathrm{~kW}$ of electrical power [8] and low field strengths, which often did not exceed $0.3 \mathrm{~T}$ before the power requirements made them uneconomical. Permanent 
magnets, although they were extremely heavy, could give fields up to $1 \mathrm{~T}$ [9-11] with very low power requirements. The advent of superconducting magnets and their proliferation, overtook their predecessors; initially with field strengths in the range of 0.35 to $0.6 \mathrm{~T}$ [12-14] and later $1 \mathrm{~T}$ and more. Superconducting magnets were considered lighter than permanent magnets and yet required no electrical power to maintain their magnetic field as did resistive magnets. Eventually, the $1.5 \mathrm{~T}$ commercial scanner became popular in 1985 and by 1998, the commercial $3 \mathrm{~T}$ imager [15] had started growing in market share.

Superconducting magnets offer higher signal-to-noise ratio, higher field strengths, higher image quality, lower lifecycle costs and generally shorter imaging times $[2,16$, 17], albeit presenting very high capital costs. Permanent magnets have a fixed field and considerably low power requirements. They permit different configurations such as open-access MRI systems [3-5]; however, they are very bulky and heavy. Resistive magnets produce weaker fields, are less expensive [18] and exhibit smaller fringe fields than superconducting magnets owing to their low fields of operation. They have over the years sought a share of popularity in the commercial sphere, however, have been disadvantaged on several fronts as discussed in the next section.

In this work, we present the motivation for low-field magnets with specific focus on resistive conductors and why it is imperative to consider a thermal management system. We proceed by presenting methods that have been applied in thermal management over the years, their advantages, limitations as well as factors to consider when selecting one method over the other.

\section{Main text}

\section{Materials and methods}

An in-depth keyword-based search was conducted in academic databases such as Google Scholar, PubMed, Science Direct, Wiley, Springer and BioMed for publications on resistive magnets. Pertinent postgraduate theses were also included in the study.

\section{Inclusion criteria}

Studies that presented magnetic field strengths below $200 \mathrm{mT}$ were considered and have been categorized as low-field (LF) magnetic field in this work. It is for such LF technologies that approaches to thermal management are regarded. Systems built from resistive conductor in the form of solid or hollow wire, thick strips of conductor as well as coils machined from resistive conductor material have been considered. Furthermore, the articles were required to have systems with successful application of magnetic resonance imaging or at least designed with intended application in the same.

\section{Exclusion criteria}

Articles that involved magnets requiring superconducting wire or cryocooling of any form have been excluded in this study. Bitter-type coils as well as hybrid coils, although presenting a resistive component have not been considered in this work. Moreover, studies involving resistive coils for gradient and radiofrequency systems were omitted in this work.

\section{Motivation \\ Motivation for use of LF MRI}

LF MRI was the breakthrough point of MRI into the commercial arena, with the first commercial MR Imagers based on either permanent magnets or resistive electromagnets, however, high-field (HF) systems quickly ousted them with expensive superconducting magnets, thus alienating developing countries. LF MRI, considered an underdog to high field systems, is lately stirring keen interest in scientists. Resistive coil-based MRI systems exhibit flexible construction and siting requirements which makes them a tenable candidate for the spread of MRI systems in Low-Middle Income Countries (LMIC) where there are less than 0.1 Magnetic Resonance imagers available per 1,000,000 people [19]. Some of the reasons cited for poor distribution and utilization of MRI units in these countries include high acquisition, infrastructural and maintenance costs, and technical expertise needed to operate and use MRI systems [20,21]. Geethanath and Vaughan [22] compared the number of MRI scanners against population, life expectancy, internet users and income group and demonstrated that resource constrained settings that have a very low number of MRI units also exhibited low life expectancy and low internet usage compared to more developed economies. This story can be changed by the adoption of LF MRI technologies. A recent review by Sarracanie and Salameh [23] cites several examples of LF MRI systems with magnetic field strengths from less the $1 \mathrm{mT}$ to $199 \mathrm{mT}$ that have given quality of images for clinical diagnosis.

Resistive LF MRI systems are substantially less expensive than HF MRI systems. The design, repair, and replacement of hardware in such systems is sustainable and inexpensive, and given their small footprint, siting requirements for the system are significantly reduced. Open MRI systems are possible with low field which makes them suitable for claustrophobic patients as well as neonatal patients who might need direct access during the imaging process [24]. Low field scanners eliminate the need for an imager to perform all MRI screenings often required with High Field systems. Dedicated scanners for specific body parts and of varying functionality and image quality are tenable with low field. 
Superconducting magnets which require about 17001 of liquid Helium [25] for operation, and increasing price and anticipated future shortages in availability of liquid Helium is creating an increasing demand for MRI magnets that are free of liquid Helium [26, 27]. LF MRI magnets have much lower cooling requirements than superconducting magnets. They are also more suitable for some NMR applications such as fast field cycling given that superconducting magnets give higher fields at the expense of slower switching and higher fabrication costs [28]. LF MRI systems allow for dedicated imaging of body parts which are small and not very easily explored with whole body scanning systems [29]. In such cases, the patient does not have to experience severe discomfort from claustrophobia in the whole-body systems. A review of commercial extremity LF MRI scanners is given by [30]. Hayashi et al. [31] and Konar and Lang [32] have made compelling arguments for the use of low field MR scanners.

\section{Motivation for cooling}

There is a renewed effort in the development of resistive coil based LF MRI systems, especially for applications in LMIC. Resistive wire based LF MRI machines are made by winding coils with many turns to generate required magnetic field for the system. During operation, current flows through the conductor wire which has a finite resistance. This resistance to the flow of current manifests as heat, also commonly known as joule losses. Conducting wire is often insulated to prevent short circuiting of the current. Magnetic field strength of a magnet depends on the current flowing through the conductor. The power deposited in a coil increases as the square of the field strength thus, maximum field strength is subject to the cooling ability of the coil.

A rise in temperature of the conducting wire, however, affects the insulation used during winding causing it to age drastically, making it the weakest link in the life of the coil [33]. Heating in a LF MRI increases the noise in the images produced and can also affect patient comfort $[34,35]$. Because of increase in temperature above the thermal limits of the insulation, serious damage of the insulation can occur, and hence short circuiting between the coil conductor and surrounding equipment. The magnetic field in resistive coils is highly susceptible to small expansions. Macovski [36] and Kedzia [37] both observed a drop in magnetic field due to adjustment of the coil positions by the slight expansion from increase in temperature of a coil. Some methods have been proposed by various authors on minimization of temperature rise in resistive coils, the following section discusses this work.

\section{Cooling methods applied}

Cooling systems can exhibit conductive, convective, or radiative modes of heat transfer. Often, a combination of these modes is experienced, although one of the modes generally exhibits greater dominance. Conductive cooling works by the transmission of heat through stationary matter; the two bodies across which heat is being transferred are in physical contact [38]. The matter is stationary on a macroscopic scale; however, on a microscopic scale, the atoms are vibrating and are in thermal motion. Convective heat transfer allows for the transfer of heat by macroscopic motion of a fluid. The convective mode of cooling can take the form of air cooling (natural or forced convection), or liquid cooling (water, oil, or any high thermal conductivity liquid and this can be by passive or active means) [39]. Heat transfer by radiation is independent of physical contact; it occurs by transmission of infrared electromagnetic waves through space. The following section discusses how different authors applied one or more heat transfer modes to their resistive coils. Table 1 presents a summary of the methods that have been applied to cool resistive magnets.

\section{Conduction cooling}

Bejan [59] exploited the idea of cooling by conduction by using a finite amount of high conductivity material to draw heat away from the source to the heat sink in cooling of electronics. Later, Gosselin and Bejan [40] applied a similar principle to a solenoid by inserting discs of high thermal conductivity material of determined thickness to separate the solenoid into sub-coils. Non-current transmitting discs were inserted to occupy a small fraction of total system length. Heat flowed axially through the windings and radially in the discs towards the heat sinks. More efficient cooling could be achieved with an increase in the amount of high conductivity material used. Radial heat transfer would be dominant even when the discs are carriers of cooling water. Furthermore, while studying the relationship between heat transfer and electromagnetic properties, it was observed that an electromagnetically optimized solenoid is smaller than one optimized both thermally and electromagnetically. A proposition into applying different cooling methods, assessing the mechanical integrity of the solenoid as well as minimizing costs in construction of such electromagnetic systems was made.

\section{Air cooling}

Tsai et al. [41] designed an open access exceptionally low field MRI system. The four coil biplanar magnet produced a magnetic field of $6.5 \mathrm{mT}$ when a current of 42.2 A was supplied and produced approximately $4 \mathrm{~kW}$ of resistive heat particularly from the outer coils. The outer Bo coils of diameter $2.10 \mathrm{~m}$ were wound using 
Table 1 A summary of cooling methods applied to resistive wire-based magnets and their challenges

\begin{tabular}{|c|c|c|c|c|c|c|c|}
\hline Author(s) & Paper Title & $\begin{array}{l}\text { Conductor } \\
\text { Type }\end{array}$ & $\begin{array}{l}\text { Cooling } \\
\text { Mode }\end{array}$ & Cooling Medium & $\begin{array}{l}\text { Closed/ } \\
\text { Open } \\
\text { System }\end{array}$ & $\begin{array}{l}\text { Cooling } \\
\text { Type }\end{array}$ & $\begin{array}{l}\text { Challenges/Future } \\
\text { work }\end{array}$ \\
\hline $\begin{array}{l}\text { Gosselin \& } \\
\text { Bejan [40] }\end{array}$ & $\begin{array}{l}\text { Constructal-theory Network of } \\
\text { Conducting Paths for Cooling a Heat } \\
\text { Generating Volume }\end{array}$ & & Conduction & $\begin{array}{l}\text { High thermal } \\
\text { conductivity discs }\end{array}$ & N/A & & $\begin{array}{l}\text { Need for liquid } \\
\text { cooling at higher } \\
\text { field strength }\end{array}$ \\
\hline $\begin{array}{l}\text { Tsai et al. } \\
{[41]}\end{array}$ & $\begin{array}{l}\text { An Open-access, Very-low-field MRI Sys- } \\
\text { tem for Posture-dependent 3He Human } \\
\text { Lung Imaging }\end{array}$ & $\begin{array}{l}\text { Square } \\
\text { solid } \\
\text { copper wire }\end{array}$ & Convection & Air & Open & & $\begin{array}{l}\text { Need for liquid } \\
\text { cooling at higher } \\
\text { field strength }\end{array}$ \\
\hline $\begin{array}{l}\text { Gardner } \\
\text { et al. [42] }\end{array}$ & $\begin{array}{l}\text { Production of a Uniform Magnetic Field } \\
\text { by Means of an End-Corrected Solenoid }\end{array}$ & $\begin{array}{l}\text { Copper } \\
\text { Ribbons }\end{array}$ & Convection & Water & & $\begin{array}{l}\text { Active/ } \\
\text { Forced }\end{array}$ & $\begin{array}{l}\text { Eddy currents from } \\
\text { Aluminum cylinder }\end{array}$ \\
\hline $\begin{array}{l}\text { Redpath } \\
\text { et al. [43] }\end{array}$ & A Low Field NMR Imager for Clinical Use & & Convection & Water & Open & $\begin{array}{l}\text { Active/ } \\
\text { Forced }\end{array}$ & $\begin{array}{l}\text { Use a closed system } \\
\text { with recirculation of } \\
\text { coolant }\end{array}$ \\
\hline $\begin{array}{l}\text { Lurie et al. } \\
\text { [44] }\end{array}$ & $\begin{array}{l}\text { Design, Construction and Use of a Large- } \\
\text { sample Field-cycled PEDRI Imager }\end{array}$ & $\begin{array}{l}\text { Copper } \\
\text { sheets }\end{array}$ & Convection & Water & & $\begin{array}{l}\text { Active/ } \\
\text { Forced }\end{array}$ & $\begin{array}{l}\text { Explore cooling in the } \\
\text { axial direction }\end{array}$ \\
\hline $\begin{array}{l}\text { Sciandrone } \\
\text { et al. [45] }\end{array}$ & $\begin{array}{l}\text { Compact Low Field Magnetic Resonance } \\
\text { Imaging Magnet: Design and } \\
\text { Optimization }\end{array}$ & $\begin{array}{l}\text { Copper } \\
\text { tape }\end{array}$ & Convection & Water & Open & $\begin{array}{l}\text { Active/ } \\
\text { Forced }\end{array}$ & $\begin{array}{l}\text { Closed system with } \\
\text { deionized water }\end{array}$ \\
\hline $\begin{array}{l}\text { Grafendorfer } \\
\text { et al. [46] }\end{array}$ & $\begin{array}{l}\text { A } 0.2 \text { T Homogeneous Resistive Knee } \\
\text { Magnet for Remotely Polarized MRI }\end{array}$ & $\begin{array}{l}\text { Solid } \\
\text { copper wire }\end{array}$ & Convection & Water & Closed & $\begin{array}{l}\text { Active/ } \\
\text { Forced }\end{array}$ & $\begin{array}{l}\text { Explore hollow } \\
\text { conductors }\end{array}$ \\
\hline $\begin{array}{l}\text { Gilbert et al. } \\
{[47]}\end{array}$ & $\begin{array}{l}\text { Design of Field-cycled Magnetic Reson- } \\
\text { ance Systems for Small Animal Imaging }\end{array}$ & & Convection & Water & Closed & $\begin{array}{l}\text { Active/ } \\
\text { Forced }\end{array}$ & $\begin{array}{l}\text { Decreased cooling } \\
\text { efficiency from } \\
\text { indirect contact of } \\
\text { coil with coolant }\end{array}$ \\
\hline $\begin{array}{l}\text { Matter et al. } \\
{[48]}\end{array}$ & $\begin{array}{l}\text { Rapid Polarizing Field Cycling in Magnetic } \\
\text { Resonance Imaging }\end{array}$ & $\begin{array}{l}\text { Square } \\
\text { hollow } \\
\text { copper }\end{array}$ & Convection & Water & & $\begin{array}{l}\text { Active/ } \\
\text { Forced }\end{array}$ & $\begin{array}{l}\text { Pressure drop and } \\
\text { possible corrosion in } \\
\text { fluid channel }\end{array}$ \\
\hline $\begin{array}{l}\text { Alford et al. } \\
\text { [49] }\end{array}$ & $\begin{array}{l}\text { Design and Construction of a Prototype } \\
\text { High-Power Bo Insert Coil for Field-Cycled } \\
\text { Imaging in Superconducting MRI Systems }\end{array}$ & $\begin{array}{l}\text { Square } \\
\text { solid } \\
\text { copper wire }\end{array}$ & Convection & Water & Closed & $\begin{array}{l}\text { Active/ } \\
\text { Forced }\end{array}$ & $\begin{array}{l}\text { Direct cooling with } \\
\text { deionized water for } \\
\text { better cooling } \\
\text { efficiency }\end{array}$ \\
\hline $\begin{array}{l}\text { Savukov } \\
\text { et al. [50] }\end{array}$ & $\begin{array}{l}\text { Non-cryogenic Anatomical imaging in } \\
\text { Ultra-Low Field Regime: } \\
\text { Hand MRI Demonstration }\end{array}$ & & Convection & Air & Open & & $\begin{array}{l}\text { Need to use forced } \\
\text { air cooling when } \\
\text { operational current is } \\
\text { increased }\end{array}$ \\
\hline \multirow[t]{2}{*}{ Busch [51] } & $\begin{array}{l}\text { Ultra-low Field MRI of Prostate Cancer } \\
\text { using SQUID Detection }\end{array}$ & Litz wire & Convection & Liquid Nitrogen & & Passive & $\begin{array}{l}\text { Hotspots were } \\
\text { formed }\end{array}$ \\
\hline & & $\begin{array}{l}\text { Hollow } \\
\text { copper } \\
\text { tubes }\end{array}$ & & Water & & $\begin{array}{l}\text { Active/ } \\
\text { Forced }\end{array}$ & $\begin{array}{l}\text { Cool between pulses } \\
\text { to minimize eddy } \\
\text { currents }\end{array}$ \\
\hline $\begin{array}{l}\text { Lips et al. } \\
\text { [52] }\end{array}$ & $\begin{array}{l}\text { Magnet Design with High Bo } \\
\text { Homogeneity for Fast-Field Cycling NMR } \\
\text { Applications }\end{array}$ & & Convection & Perfluoropolyether & Closed & $\begin{array}{l}\text { Active/ } \\
\text { Forced }\end{array}$ & \\
\hline $\begin{array}{l}\text { Morgan et al. } \\
\text { [53] }\end{array}$ & A Readout Magnet for Prepolarized MRI & & Convection & Air & & Passive & $\begin{array}{l}\text { Need for forced } \\
\text { cooling at higher } \\
\text { magnetic strengths }\end{array}$ \\
\hline $\begin{array}{l}\text { Bidinosti } \\
\text { et al. [54] }\end{array}$ & $\begin{array}{l}\text { In Vivo NMR of Hyperpolarized } 3 \mathrm{He} \text { gas in } \\
\text { Human Lung at Very Low Magnetic Fields }\end{array}$ & $\begin{array}{l}\text { Solid } \\
\text { copper wire }\end{array}$ & Convection & Air & & Passive & $\begin{array}{l}\text { Need for forced } \\
\text { cooling at higher } \\
\text { magnetic strengths }\end{array}$ \\
\hline $\begin{array}{l}\text { Sousa et al. } \\
{[55]}\end{array}$ & $\begin{array}{l}\text { Design of Nuclear Magnetic Resonance } \\
\text { Fast Field Cycling Air Cored Magnet }\end{array}$ & $\begin{array}{l}\text { Copper } \\
\text { bar/wire }\end{array}$ & Convection & Transformer oil & Closed & $\begin{array}{l}\text { Active/ } \\
\text { Forced }\end{array}$ & $\begin{array}{l}\text { Heating of one end } \\
\text { of coil due to } \\
\text { direction of cooling. }\end{array}$ \\
\hline $\begin{array}{l}\text { Hilschenz } \\
\text { et al. [56] }\end{array}$ & $\begin{array}{l}\text { Remote detected Low-Field MRI using an } \\
\text { optically pumped atomic magnetometer } \\
\text { combined with a liquid cooled pre- } \\
\text { polarization coil }\end{array}$ & $\begin{array}{l}\text { Litz copper } \\
\text { wire }\end{array}$ & Convection & Silicon Oil & Closed & $\begin{array}{l}\text { Active/ } \\
\text { Forced }\end{array}$ & $\begin{array}{l}\text { Low flowrate } \\
\text { Highly viscous } \\
\text { coolant }\end{array}$ \\
\hline $\begin{array}{l}\text { Lother et al. } \\
{[57]}\end{array}$ & $\begin{array}{l}\text { Design of a mobile, homogeneous, and } \\
\text { efficient electromagnet with a large field }\end{array}$ & $\begin{array}{l}\text { Solid } \\
\text { copper wire }\end{array}$ & Convection & Air & Open & Active & $\begin{array}{l}\text { Insufficient for higher } \\
\text { field strengths }\end{array}$ \\
\hline
\end{tabular}


Table 1 A summary of cooling methods applied to resistive wire-based magnets and their challenges (Continued)

\begin{tabular}{|c|c|c|c|c|c|c|c|}
\hline Author(s) & Paper Title & $\begin{array}{l}\text { Conductor } \\
\text { Type }\end{array}$ & $\begin{array}{l}\text { Cooling } \\
\text { Mode }\end{array}$ & Cooling Medium & $\begin{array}{l}\text { Closed/ } \\
\text { Open } \\
\text { System }\end{array}$ & $\begin{array}{l}\text { Cooling } \\
\text { Type }\end{array}$ & $\begin{array}{l}\text { Challenges/Future } \\
\text { work }\end{array}$ \\
\hline & of view for neonatal low-field MRI & & & & & & \\
\hline $\begin{array}{l}\text { Obungoloch } \\
\text { [58] }\end{array}$ & $\begin{array}{l}\text { Development of Ultra Low Field Magnetic } \\
\text { Resonance Imaging for Diagnosis of } \\
\text { Hydrocephalus in Developing Countries }\end{array}$ & $\begin{array}{l}\text { Solid } \\
\text { copper wire }\end{array}$ & Convection & Air & & Passive & $\begin{array}{l}\text { Need to apply forced } \\
\text { cooling with } \\
\text { increased currents }\end{array}$ \\
\hline
\end{tabular}

AWG 6 square copper wire bound by high viscosity thermally conductive epoxy against an L-shaped aluminum channel to which a silver-based thermally conductive paste was applied to enhance conductive cooling. The inner Bo coils were wound and bound in the same way as the outer coils to Nylatron, which was mounted onto aluminum flanges. The aluminum channel functioned as a large heat sink; however, most of the cooling was done by convective air flow. Coil surface temperatures did not rise beyond $70{ }^{\circ} \mathrm{C}$. The power system was cooled using a $2-\mathrm{kW}$ recirculating liquid chiller to pump ethylene-glycol and water mixtures at $15^{\circ} \mathrm{C}$ through two 0.5-in. copper tubes. The pumping was done continuously during imaging and the temperature of the cooling tubes did not exceed $40^{\circ} \mathrm{C}$.

In Non-cryogenic anatomical imaging in the ultra-low field regime: Hand MRI demonstration, Savukov et al. [50] demonstrated the use of atomic magnetometers with an ultra LF non-cryogenic scanner that was light weight, inexpensive and compact, without the need for shielding. The static magnetic field was achieved using a 4-coil Lee-Whiting configuration wound on a $33 \mathrm{~cm}$ diameter G-10 cylinder. A short-air cooled solenoid generated a prepolarizing field of $0.1 \mathrm{~T}$. Although little detail is given on the design of the cooling system, the authors noted that the system was capable of running on twice the amount of current they used in the study and would therefore have to include a forced air cooling system to control thermal heating.

Lother et al. [57] also designed a mobile four coil resistive magnet wound with enameled copper wire and mounted on steel plates. The compact design allowed the fitting of uniquely designed gradient coils to each side for efficient space use. The magnet was designed for air cooling provided the power dissipated did not exceed $500 \mathrm{~W}$ when operating at $23 \mathrm{mT}$. Cooling efficiency was facilitated by steel plates that doubled as magnetic shields. Estimated power dissipation was calculated for $2 \mathrm{~kW}$ and $5 \mathrm{~kW}$ for field strengths of $50 \mathrm{mT}$ and $80 \mathrm{mT}$ respectively, which would have needed liquid cooling.

\section{Liquid cooling}

Gardner et al. [42] applied liquid cooling to a solenoid for application to beta-ray spectrometry. The $47.5 \mathrm{mT}$ solenoid was wound using thin copper ribbons of width
$1 \frac{1}{4}$ in and thickness $0.021 \mathrm{in}$. The copper ribbons had a single layer of insulation facilitating heat transfer in the radial direction to the heat transfer plate. Heat transfer between the insulation and heat transfer plate was promoted by applying silicone Silastic to fill any air gaps, and the whole coil assembly mounted onto an aluminum cylinder. The thermal gradient was enhanced by running water in alternate directions through $\frac{3}{16}$ in copper tubes soldered to the heat transfer pipes. At full power (10 $\mathrm{kW}, 475 \mathrm{G})$, the temperature of the coils was found to be $5{ }^{\circ} \mathrm{C}$ above that of the cooling fluid. A thermal analysis of the cooling system was not presented, nor was there any comment on possible eddy currents from the aluminum cylinder or cooling system.

In 'A Low Field NMR Imager for Clinical Use', Redpath et al. [43] also applied water cooling to a four-coil air-cored resistive vertical field electromagnet with a central field of $0.08 \mathrm{~T}$. The $1.9 \mathrm{~m}$ high and 2 tons magnet demanded $25 \mathrm{l} / \mathrm{min}$ of water to reduce temperature rise and an additional $7.5 \mathrm{l} / \mathrm{min}$ of water to cool the power supply. The cooling water was supplied from a header tank and was not recirculated in the system but run into the drain.

A combination of air and water cooling was, however, applied by Lurie et al. [44, 60], while designing and constructing a large Proton-electron Double-Resonance Imager. The primary magnet, a whole-body sized permanent magnet with a vertically oriented field of $59 \mathrm{mT}$, was cooled by blowing air from the room using a fan over the magnet's thermal cover. Although the magnet had a large thermal time constant of a few days, cooling was done to obviate inhomogeneity in the magnetic field from thermal stresses. The room temperature was kept at $22{ }^{\circ} \mathrm{C}$ by an air conditioner. The secondary magnet was a resistive magnet of copper sheets wound in saddle configuration. It was water cooled on the outer surface of the cylinder that holds it; however, no additional information was shared on the construction and operation of the system.

Sciandrone et al. [45] designed and optimized a low field imaging magnet. The magnet, wound with copper tape, $6.3 \mathrm{~mm}$ wide and 2 in thick had a magnetic field strength of $0.1 \mathrm{~T}$ and power requirement of $2.2 \mathrm{~kW}$. The eight coils that made up the magnet were mounted on a 
copper cylinder and kept in position by aluminum rings. The copper cylinder was cooled using ordinary water in an open circuit which confined the temperature rise of the copper cylinder to $40^{\circ} \mathrm{C}$. They recommended the use of deionized water in a closed-circuit cooling system.

Lips et al. [52] designed a fast field cycling magnet of magnetic field $0.95 \mathrm{~T}$ at $800 \mathrm{~A}$ of current. Six coaxially mounted layers of thick cylindrical coils of varying coil width were cooled radially with perfluoropolyether flowing from the top and bottom on the inside of the inner layer to the outside of the windings. The flow was turbulent and directed in such a way that it was strongest at the points where the windings were thickest. No significant heat gradient was observed inside the coil in the axial direction. Water in an internal circuit was used to cool the coolant, maintaining coolant temperature of about $12{ }^{\circ} \mathrm{C}$ via a $50-\mathrm{kW}$ plate heat exchanger while conductor temperature was on average $26^{\circ} \mathrm{C}$.

Moreover, Grafendorfer et al., [46] designed a fourcoil homogeneous $0.2 \mathrm{~T}$ water cooled resistive knee magnet, with water carrying copper tubes sandwiched between cooling plates attached to the coil. The cooling plates were split every 22.5 degrees to minimize losses from eddy currents. The temperature rise at the coil's hottest spots capped at $40^{\circ} \mathrm{C}$ when the chilled water flowed at $15.14 \mathrm{l} / \mathrm{min}$. The power dissipated was $17.5 \mathrm{~kW}$. Hollow conducting wire was proposed for enhanced thermal conductivity.

A detailed construction of a LF MRI cooling system has been given by Gilbert et al. [47]. Forced water aluminum cooling plates were used for heat transfer in their field cycling system for imaging small animals. The cooling plates were placed at each face of each coil of the main magnet and were sandwiched within the polarizing magnet as well as at its ends. A radial gap of about $7 \mathrm{~cm}$ was allowed between the polarizing and the readout magnets for cooling tubes and support systems. In [61], two thermal models were developed to assess the thermal performance of the magnets; equilibrium and dynamic models which they validated by experiment. It was observed that the temperatures of the polarizing magnet were limited to $150^{\circ} \mathrm{C}$ and those of the readout magnet rose only slightly owing to the forced water cooling and a low duty cycle of $10 \%$. A flow rate of $91 / \mathrm{min}$ was used for both the readout and polarizing magnets. Both magnets were driven by a continuous current of $100 \mathrm{~A}$ and the temperature rise did not exceed $20^{\circ} \mathrm{C}$ during a 5 -min scan period [62]. They also noted that the time between successive operations of the system was the most important cooling parameter in thermal performance. There was generally a good correlation between the dynamic model and the experiment, although oversimplification of the models could have caused the divergence in some values [61].

In contrast, Matter et al. [48] used square hollow conductor wire in construction of a LF pre-polarized MRI system. The coil, $12.7 \mathrm{~cm}$ inner diameter was designed to image a human wrist. The polarizing coil, a segmented solenoid connected in series was water cooled. The cooling fluid was passed through the conductor as a means of removing heat from the system, however, to increase heat transfer, the water channels were connected in parallel. This allowed them to achieve currents as high as $200 \mathrm{~A}$ and a field strength of $0.42 \mathrm{~T}$. The system efficiently removed $16 \mathrm{~kW}$ dissipated as heat from the coils. It was purported that with water-cooling, polarizing fields as high as $1 \mathrm{~T}$ are plausible.

Sousa et al. [55] designed a $1.6 \mathrm{~T}$ Fast Field Cycling Air Cored Magnet for NMR. The magnet was optimized for maximum current density, minimum power losses and minimum volume. Driven by a current of $200 \mathrm{~A}$, $78.4 \mathrm{~kW}$ of power was dissipated, however, cooling layers were optimized within the design to ensure efficient cooling with the coils occupying minimal volume. Transformer oil flowed through the hydraulic layers as a coolant from one end of the coil to the other through the full length of the coil [63].

Alford et al. [49] designed a Bo insert coil for use in a superconducting MRI. The solenoid coil was wound with AWG4 square cross-section wire, reinforced with epoxy. One hundred meters of $6.35 \mathrm{~mm}$ OD thin-walled Teflon tubing was wound proximal to the inner and outer surfaces of the magnets for cooling of both the primary and shield (108 turns AWG7 Litz rectangular cross section wire) magnets. Thermal conductivity was facilitated by potting the whole assembly in thermally conductive epoxy resin (part \#51-3100). Observation during testing showed relatively poor conductivity across the Teflon cooling tubes; thus, the limiting factor to cooling performance. A thermal resistance of $0.0175{ }^{\circ} \mathrm{C} / \mathrm{W}$ was measured for a supply of $61 / \mathrm{min}$ of chilled water for cooling. It was proposed that the performance of the insert be made better by replacement of the Teflon cooling tubes with direct cooling using deionized water to enhance cooling efficiency.

Busch [51] used ultra-low field MRI for prostate cancer measurements. The static field magnet was a biplanar four coil magnet although only the larger coil of diameter $1.37 \mathrm{~m}$ and 40 turns was implemented. The initial pre-polarizing coil was wound from Litz wire and cooled by liquid nitrogen via special cooling channels designed within the coil. Cooling of the coil was only done until an overall resistance of $1.4 \Omega$ was reached, although the resistance would rise to as high as $2.5 \Omega$. During operation, cooling would be discontinued to avert instauration of hotspots from uneven cooling 
which could affect insulation of the wire at uncooled locations. Cooling would however be done just before imaging to thermalize the wire. An attempt to cool the Litz wire with water decreased the self-resonant frequency of the coil given that the high dielectric constant of water substantially increased the turn-turn capacitance of the coil.

A decision to change the pre-polarizing coil to allow for higher current densities and magnetic field resulted in the use of hollow wire conductors with provision for water cooling. The new coil consisted of 240 turns and produced a field of $150 \mathrm{mT}$ at $200 \mathrm{~A}$. The coil dissipated $10 \mathrm{~kW}$ of heat and required $4 \mathrm{l} / \mathrm{min}$ of cooling water to keep the temperature rise below $40{ }^{\circ} \mathrm{C}$ at $50 \%$ duty cycle. Heat dissipation would rise to as high as $20 \mathrm{kw}$ when the coil was powered at 200A. However, the watercooled coil caused eddy currents to flow around the aluminum shielded room that was made from $6.4 \mathrm{~mm}$ thick Aluminum plates. A decrease in the thickness of the Aluminum shield minimized this noise. During imaging of a phantoms at $120 \mathrm{mT}$, a waiting time of $1.4 \mathrm{~h}$ was allowed with in the total scanning time of $2.4 \mathrm{~h}$ so the coil could cool between pulses, although a higher flow rate would decrease and possibly eliminate this time [51].

Hilschenz et al. [56] however registered a different experience with their Litz wire pre-polarizing coil. The coil was wound from a $3.6 \mathrm{~mm}$ diameter, 19 strands Litz copper wire. The 300 turns were arranged in 10 layers and immersed in silicon oil as coolant, enclosed within an acrylic chassis. The coil was wound in a manner that permitted insertion of carbon bars as spacers for coolant to flow between every layer. This considerably improved cooling efficiency. The use of silicon oil inhibited sparks from the high voltages for an increased switch off rate. With the coil running at $30 \mathrm{~A}, 3 \mathrm{~s}$ on and $1 \mathrm{~s}$ off and a duty cycle of $75 \%$, the temperature of the coils did not exceed $40^{\circ} \mathrm{C}$. The pressure pump used to circulate coolant worked at $90 \%$ of its power limit, albeit the flow rates of coolant were a limiting factor due to its high viscosity. Given the magnetic field from Bp coils need not be homogeneous, designing of the coil with intermittent spacers may be acceptable for such a system. However, it is fundamental to assess the effect of the spacers on homogeneity of the field strength when such a design approach is applied to static magnetic field coils.

\section{No cooling}

Moreover, Morgan et al. [53] proposed the application of no cooling while designing a readout magnet for Prepolarizing MRI. A comparison of two designs based on an equation to minimize temperature rise in the system was made under the assumption of an exceptionally large thermal time constant to exclude forced cooling.
The Helmholtz system was bulky and of a high-power requirement, implying a possible need for cooling. The power requirements and heating load of the system could be decreased by adding weight to an already heavy system. The six-coil system, however, was designed for a magnetic field of $0.07 \mathrm{~T}$ and dissipated $6.7 \mathrm{~kW}$ of power at $100 \mathrm{~A}$. After homogenizing the field, applying an exceptionally large thermal time constant to estimate the cross-sectional area of the coils such that the temperature rise was limited to a set amount, permitted elimination of active cooling of the system altogether. A slow heating rate of $6^{\circ} \mathrm{C} / \mathrm{min}$ was applied during design of the coils and at $1 \mathrm{MHz}$ and a current of $12.7 \mathrm{~A}$, a temperature rise of $20^{\circ} \mathrm{C}$ was expected over a period of $6 \mathrm{~min}$. A temperature rise of $200^{\circ} \mathrm{C}$ would be expected in the same time period at $3 \mathrm{MHz}$, thus addition of forced cooling by air or water to minimize temperature rise in the conductors would be advantageous.

Bidinosti et al. [54] in their work on studying human lungs at very low magnetic fields implemented a magnet of seven co-axial coils of 144 turns each wound from copper wire $2 \mathrm{~mm}$ in diameter. The coils were wound on an aluminum annulus and required no forced cooling at the desired magnetic field of $6 \mathrm{mT}$ driven by a current of $8.7 \mathrm{~A}$ and $940 \mathrm{~W}$ of power. The low magnetic field made active cooling unnecessary.

Obungoloch [58] developed an Ultra LF MRI for diagnosis of hydrocephalus. The system consisted of a static magnetic field coil (Bm coil) operated at $2.66 \mathrm{mT}$, a prepolarizing coil, (Bp coil), Radiofrequency and gradient coils. The Bp coil, a solenoid constructed from enameled copper wire AWG 10 had a total of 1140 turns and gave a magnetic field strength per unit current of $5 \mathrm{mT} / \mathrm{A}$ at the center of the coil when supplied with a current of 10 A. During testing of the system, over a period of $90 \mathrm{~min}$, temperature of the imaging volume and the Bp coil were simultaneously measured. A relatively constant temperature was measured in the imaging volume while that of the coil increased considerably by as much as $80^{\circ} \mathrm{C}$, thus a proposition to use fans to keep temperature rise manageable. The system had a combined power utilization of $550 \mathrm{~W}$.

\section{Discussion and conclusions}

\section{Discussion}

The choice of cooling system for use in an MRI machine depends on the magnetic field strength requirement of the magnet, which is dependent on the material of the magnet. Most LF resistive magnets are built from three common methods: (1) enameled solid wire, (2) hollow copper wire or (3) tape conductors. Each method has its own advantages and challenges to cooling. In case (1), cooling is often done at the surface of the coil; heat is transferred to the cooling surface via an enamel 
insulator which in many cases is the limiting factor. The likelihood of creation of hotspots in such a coil is remarkably high due to the creation of a thermal gradient from slow heat transfer via the insulation. Solid conducting wire was applied by $[41,49,55,63]$. Hollow conductors (2) have been used by [48, 51]. Cooling is done by pumping the coolant through the center of the conductor; there are no thermal barriers because direct cooling is used, however, the costs of running such a system are high resulting from the hydraulic requirements for coolant circulation. The third case (3) was applied by $[44,45,60]$. The coils are surface cooled at their faces or edges, and present better heat transfer than (1) because the insulation is only between layers. The magnetic field strength of a magnet depends on the current flowing through the conductor, yet the power deposited in a coil increases as the square of the field strength, therefore, the maximum field strength is tied to the ability to cool the coil.

In many of the systems reviewed, addition of a cooling system was a necessity except with [53] who applied a slow heating rate to eliminate the need for cooling and $[54,58]$ who were working with sufficiently low magnetic fields and currents that allowed passive convection without overheating of the coils. Conduction based cooling $[40]$ and air cooling $[41,57]$ have been applied in situations where the heat load was low enough not to cause destruction of the conductor. However, it ceases to be effective when magnetic field requirements are scaled up, thus, necessitating a form of liquid cooling. The use of conductive or air cooling is often limited to heat transfer at the outermost surfaces of the magnet. This can be overcome by modifying a conduction-based cooling system by adding strips of high conductivity material between coil layers during winding that will transfer heat to the discs between the coils. The surface area over which air cooling is possible can be increased by adding spacers between subsequent layers thus availing more channels for air flow within the coil. These modifications introduce new challenges, and such include decreased field homogeneity, the need to use more conducting wire or strips, increased system weight. Table 2 is a summary of the advantages and limitations of the cooling systems reviewed in this work.

The use of liquid cooling excels above conductive and air cooling as an effective method of heat removal [51, $52,55,56,63]$. Authors such as $[42-48,51,56,60,62]$ used water, whereas liquid nitrogen [51], perfluoropolyether [52], transformer oil [55, 63] and silicon oil [56] have also been used as coolant. Liquid cooling can either be applied in a closed or open loop cooling system. In an open loop system as in [45], coolant drains out during operation. This system is less expensive, easier to construct and has lower power requirements. Raw water is often used owing to its ready availability. In closed cooling systems, the coolant is recirculated through the cooling channels after its heat is removed by another fluid via a heat exchanger. Liquids including water can be used as coolant [52, 55, 56, 63]. Closed systems permit the use of other coolants that are more efficient and have milder effects on the coil than water, although they present an environmental risk in the event of leakage and eventual disposal at the end of the working life of the system. The use of ordinary water in such systems can eventually cause corrosion especially in hollow conductors due to the high hydraulic requirements and potential shocks and sparking for coil cases (1) or (3) if there is a leakage.

The decision on the location of cooling pathway and channels is as essential in the management of temperature rise as the choice of cooling method and medium. The resolution to select direct cooling over indirect cooling hinges on different factors. This decision is often unique to the magnet requirements. However,

Table 2 Advantages and limitations of different cooling methods

\begin{tabular}{|c|c|c|}
\hline $\begin{array}{l}\text { Cooling } \\
\text { Method }\end{array}$ & Advantages & Limitations \\
\hline Conduction & $\begin{array}{l}\text { - Good with low current density systems. } \\
\text { - No moving parts required. } \\
\text { - Can be coupled with convective cooling methods. }\end{array}$ & $\begin{array}{l}\text { - There is a limit to how much heat transfer material is to be used. } \\
\text { - Not suitable for high current density values. } \\
\text { - Significant increase in system weight if more heat conductive material } \\
\text { is added. } \\
\text { - Eddy currents in case of excess material [42] and from changing fields }\end{array}$ \\
\hline Air cooling & $\begin{array}{l}\text { - Cooling medium is readily available. } \\
\text { - Can easily be coupled with conductive cooling and } \\
\text { indirect liquid cooling. } \\
\text { - Dry method hence no fear of shocks from leakage. }\end{array}$ & $\begin{array}{l}\text { - Limited to current densities of } 2 \mathrm{~A} / \mathrm{mm}^{2} \text {. } \\
\text { - Low coefficient of heat transfer (between 2.5-10 (natural convection) } \\
10-500 \mathrm{~W} / \mathrm{m}^{2} \mathrm{~K} \text { (forced convection) [64]). } \\
\text { - Often bulky with high space requirements. }\end{array}$ \\
\hline $\begin{array}{l}\text { Liquid } \\
\text { cooling }\end{array}$ & $\begin{array}{l}\text { - Relatively high coefficient of heat transfer (100-15,000 W/ } \\
\left.\mathrm{m}^{2} \mathrm{~K}[64]\right) \\
\text { - Compact design is possible hence lower space } \\
\text { requirements. } \\
\text { - No thermal barriers when direct cooling through hollow } \\
\text { conductors is used }\end{array}$ & $\begin{array}{l}\text { - Possible electric shocks in case of leakages } \\
\text { - Corrosion of cooling channels due to high flow rate and pressure } \\
\text { requirements } \\
\text { - Additional power and operational costs from pumping }\end{array}$ \\
\hline
\end{tabular}


for any magnet design, in addition to the strength of the magnetic field, the following should be considered. 1) The coil configuration; the arrangement of coils to create the desired magnetic field is fundamental to the decision on a cooling system. Some configurations such as Lee-Whiting [65], Merritt [66] have significant separation between the coils which increases the surface area available for cooling compared with coil size. Long and thick solenoids are more challenging to cool. 2) The application of the system; the system can be a whole body or dedicated imager. It can be fixed or movable or required to work in a constrained environment or the field. A portable system will require a compact thermal management system, which may not be as critical for a stationary system. 3) The demand on the system during operation; this includes the number of hours of operation and the time allowed between screenings. Longer hours of operation and shorts intervals between screenings place high demands on the cooling system. 4) The space and weight requirements include the amount of space available for the system and its components and the maximum weight the system should have. When more space is available for the imaging system, a larger cooling system that could be less financially demanding can be considered. Available space can also mean that the volume of the magnet(s) can be larger, therefore, conductors with lower resistance can be used. This will decrease the thermal management requirements. 5) The energy cost of operating a cooling system should be considered. LMIC settings with low access to electricity and high electricity tariffs can benefit from systems with low running costs.

Therefore, one approach towards improving thermal management would be to design short and thick coils with edge cooling given that the distance over which heat transfer to the cooling channels will be short. Radial cooling of such coils is possible; however, the coils end up thicker. Consideration of coil configurations such as Helmholtz, Lee-Whiting and Merrit designs give considerably uniform field homogeneity and allow for short and thick designs. Long and thick coils can also be considered especially when the field requirements are high. However, it would be necessary to split the coil, preferably in the axial direction to provide short distances over which heat transfer can occur.

\section{Conclusion}

The recent increased interest in low field magnetic resonance imaging necessitates critical consideration of the hardware limitations to its growth. Resistive magnets launched superconducting magnets that eventually overtook them for diverse reasons. One worth noting is their low fields and yet high-power requirements, hence the need for cooling. Several approaches to thermal management of LF MRI systems have been reviewed in this work. The decision on which method of cooling to apply depends on various factors, especially the design and construction of the magnet. Great costs are incurred when the incorporation of a cooling system is an afterthought or inadequate to meet the operational need of the magnet. Therefore, anticipation of future magnetic and cooling requirements without the need to redesign the cooling system or use unanticipated energy to operate the entire system is essential right from the design of the magnet.

\section{Abbreviations}

AWG: American Wire Gauge; HF: High-Field; LF: Low-Field; LMIC: Low-Middle Income Country; MRI: Magnetic Resonance Imaging; NMR: Nuclear Magnetic Resonance; OD: Outer Diameter

\section{Acknowledgements}

Not applicable.

\section{Authors' contributions}

FN: Acquisition and interpretation of data, drafting of work. JO: Definition of scope, revision of work. SJS: Concept development. TMT: Guidance on research writing, revision, and corrections. All authors have read and approved the manuscript.

\section{Funding}

This work was funded by US National Institutes of Health grant. Grant number: R01HD085853. This grant supported SJS, JO and FN.

Availability of data and materials

Not applicable.

Ethics approval and consent to participate

Not applicable.

Consent for publication

Not applicable.

Competing interests

The authors declare that they have no competing interests.

\section{Author details}

'Department of Biomedical Engineering, Mbarara University of Science and Technology, Mbarara, Uganda. ${ }^{2}$ Department of Mechanical Engineering, Mbarara University of Science and Technology, Mbarara, Uganda. ${ }^{3}$ Centre for Neural Engineering, Departments of Engineering Science and Mechanics, Neurosurgery, and Physics, The Pennsylvania State University, Pennsylvania, USA.

Received: 12 July 2020 Accepted: 2 February 2021

Published online: 12 February 2021

References

1. Lauterbur P. Image formation by induced local interactions: examples employing NMR. Nature. 1973;242:190-1.

2. Morrow G. Progress in MRI Magnets. IEEE Trans Appl Supercond. March 2000;10(1):744-51.

3. Podol'skii A. Permanent-magnet assemblies for magnetic resonance imaging devices for various purposes. IEEE Trans Magn. 2002;38(2):1549-52.

4. Podol'skii A. Development of permanent magnet assembly for MRI devices. IEEE Trans Magn. 1998;34(1):248-52.

5. Abele MG, Rusinek H. Permanent conical magnet for interventional magnetic resonance imaging. IEEE Trans Magn. 2004;40(5):3382-6.

6. Hutchison J, Edelstein W, Johnson G. A whole-body NMR imaging machine. J Phys E Sci Instrum. 1980;13:947-55.

7. Hoult D, Golstein S, Caponiti J. Electromagnet for nuclear MAgnetic resonance imaging. Rev Sci Instrum. 1981;52:1342-51. 
8. Kathiravan S, Kanakaraj J. A review on potential issues and challenges in MR imaging. Sci World. 2013;2013(783715):1-10.

9. Haishi T, Uematsu T, Matsuda Y, Kose K. Development of a 1.0 T MR microscope using a Nd-Fe-B permanent magnet. Magn Reson Imaging. 2001;19:875-80

10. Zhang X, Mahesh V, Ng D, Hubbard R, Ailiani A, O'Hare B, Benesi A, Webb A. Design, construction and NMR testing of a 1 tesla Halbach. In: COMSOL Users Conference. Boston; 2005.

11. Tee SS, DiGialleonardo V, Eskandari R, Jeong S, Granlund KL, Miloushev V, Poot AJ, Truong S, Alvarez JA, Aldeborgh HN, Keshari KR. Sampling Hyperpolarized Molecules Utilizing a 1 Tesla Permanent Magnetic Field. Sc Rep. 2016;6:1-6.

12. Alfidi RJ, Haaga JR, Yousef SJE, Bryan PJ, Fletcher BD, LiPuma JP, Morrison SC, Kaufman B, Richey JB, Hinshaw WS, Kramer DM, Yeung HN, Cohen AM,

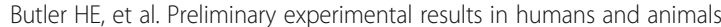
with a superconducting, whole-body, nuclear magnetic resonance scanner. Radiology. 1982;143:175-81.

13. Kneeland BJ, Knowles JR, Cahill PT. Magnetic resonance imaging systems: optimization in clinical use. Radiology. 1984;153:473-8.

14. Edelman RR, Shoukimas GM, Stark DD, Davis KR, New PFJ, Saini S, Rosenthal DI, Wismer GL, Brady TJ. High-resolution surface-coil imaging of lumbar disk disease. AJR. 1985;144:1123-9.

15. Edelman RR. The history of MR imaging as seen through the pages of radiology. Radiology. 2014;273(2):S181-200.

16. Orrison WW, Stimac GK, Stevens EA, LaMasters DL, Espinosa MC, Cobb L, Mettler FA. Comparison of $\mathrm{CT}$, low-field-strength $\mathrm{mr}$ imaging, and highfield-strength MR imaging. Radiology. 1991;181(1):122-7.

17. Cosmus TC, Parizh M. Advances in whole-body MRI magnets. IEEE Trans Appl Supercond. 2011;21(3):2104-9.

18. Kaufman L, Kramer D, Carlson J, Arakawa M. Low-field whole body systems. In: Encyclopedia od Magnetic Resonance; 2007.

19. World Health Organisation, "Global health observatory data repository: medical equipment data by country," 2016. [Online]. Available: http://apps. who.int/gho/data/node.main.510. (Accessed 2020).

20. Ogbole G, Adeyomoye AO, Badu-Peprah A, Mensah Y, Nzeh DA. Survey of magnetic resonance imaging availability in West Africa. Pan Afr Med J. 2018. 30.

21. Wald LL, McDaniel PC, Witzel T, Stockmann JP, Cooley CZ. Low-cost and portable MRI. J Magn Reson Imaging. 2019:52(3);686-96.

22. Geethanath S, Vaughan JT Jr. Accessible magnetic resonance imaging: a review. J Magn Reson Imaging. 2019:49(7);e65-77.

23. Sarracanie M, Salameh N. Low-field MRI: How low can we go? A fresh view on an old debate. Front Physiol. 2020;8(172):1-14.

24. Marques JP, Simonis FFJ, Webb AG. Low field MRI: an MR physics perspective. J Magn Reson Imaging. 2019;49:1528-42.

25. Roshini TV, Subramaniam K. A novel laser cooling system for MRI scanner using soft computing. Int J Sci Eng Res. 2017;8(10):133-40.

26. Lvovsky Y, Stautner EW, Zhang T. Novel Technologies and configurations of superconducting magnets for MRI. Superconductive Sci Technol. 2013; 26(093001):1-71.

27. Patel D, Hossain MA, Qui W, Jie H, Yamauchi Y, Maeda M, Tomsic M, Choi S, Kim J. Solid cryogen: a cooling system for future MgB2 MRI magnet. Sci Rep. 2017;7(1):1-8

28. Blanz M, Rayner TJ, Smith JA. A fast field-cycling NMR/NQR spectrometer. Meas Sci Technol. 1993:4:48-59.

29. Arbogast-Ravier S, Xu F, Choquet P, Brunot B, Constantinesco A. Dedicated low-field MRI: a promising low cost-technique. Med Biol Eng Comput. 1995; 33:735-9.

30. Ghazinoor S, Crues JV III. Low field MRI: a review of the literature and our experience in upper extremity imaging. Clin Sports Med. 2006;25:591-606.

31. Hayashi N, Watanabe Y, Masumoto T, Mori H, Aoki S, Ohtomo K, Okitsu O, Takahashi T. Utilization of low-field MR scanners. Magn Reson Med Sci. 2004; 3(1):27-38.

32. Konar M, Lang J. Pros and cons of low field magnetic resonance imaging in veterinary practice. Vet Radiol Ultrasound. 2011;52(Supp. 1):S5-S14.

33. Berube J-N, Aubin J. Transformer winding hot spot temperature determination. Quebec: Electric Energy T\&D Magazine; 2007.

34. Abuzinadah A, Dobaie A, Khashoggi K, Wazzan M, Jamjoum G. Design and Impelmentation of a modified cooling system for MRI scanner to enhance image quality. Int J Curr Res. 2016:8(12):44284-95.

35. Chu KC, Rutt BK. MR gradient coil heat dissipation. MRM. 1995;34:125-32.
36. Macovski A. A low-cost, high quality MRI breast scanner using prepolarization; 1999.

37. Kedzia P, Czechowski T, Baranowski M, Jurga J, Szczesniak E. Analysis of unifomity of magnetic field generated by the two-pair coil system. Appl Magn Reson. 2013;44(5):605-18.

38. Lienhard JH IV, Lienhard JH V. A heat transfer textbook; 2001. https://doi. org/10.1016/j.applthermaleng.2017.01.090.

39. Popescu M, Staton D, Boglietti A, Cavagnino A, Hawkins D, Goss J. Modern heat extraction systems for electrical machines - a review. In: 2015 IEEE Workshop on Electrical Machines Design, Control and Diagnosis (WEMDCD). Torino: IEEE; 2015.

40. Gosselin L, Bejan A. Constructal thermal optimization of an electromagnet. Int J Thermal Sci. 2004:43:331-8.

41. Tsai L, Mair R, Rosen M, Patz S, Walsworth R. An open-access, very-low-field MRI system for posture-dependent 3He human lung imaging. J Magn Reson. 2008;193:274-85. https://doi.org/10.1016/j.jmr.2008.05.016.

42. Gardner ME, Jungerman JA, Lichtenstein PG, Patten CG. Production of a uniform magnetic field by means of an end-corrected solenoid. Rev Sci Instrum. 1960:31(9):929-34

43. Redpath TW, Hutchison JMS, Eastwood LM, Selbie RD, Johnson G, Jone RA, Mallard JR. A low field NMR imager for clinical use. J Phys E: Sci Instrum. 1987;20:1228-34.

44. Lurie DJ, Foster MA, Yeungy D, Hutchison JMS. Design, construction and use of a large-sample field-cycled PEDRI imager. Phys Med Biol. 1998;43: 1877-86.

45. Sciandrone M, Placidi G, Testa L, Sotgiu A. Compact low field magnetic reonance imaging magnet: design and optimization. Rev Sci Instrum. 2000; $71 \cdot 1534-8$.

46. Grafendorfer T, Thompson L, Macovski A, Scott G, Conolly SM. A 0.2 T homogeneous resistive knee magnet for remotely polarized MRI. In: International Society for Magnetic Resonance in Medicine. Florida: ISMRM; 2005.

47. Gilbert KM, Handler WB, Scholl TJ, Odegaard JW, Chronik BA. Design of Field-cycled Magnetic Resonance Systems for small animal imaging. Phys Med Biol. 2006;51:2825-41

48. Matter NI, Scott GC, Granfendorfer T, Macovski A, Conolly SM. Rapid polarizing field cycling in magnetic resonance imaging. IEEE Trans Med Imaging. 2006:25(1):84-93.

49. Alford JK, Scholl TJ, Handler WB, Chronik BA. Design and construction of a prototypehigh-power BOinsert coil for field-cycledimaging in superconducting MRI systems. Concepts Magn Reson Part B: Magn Reson Eng. 2009;35B(1):1-10.

50. Savukov I, Karaulanov T, Catro A, Volegov P, Matlashov A, Gomez J, Espy M. Non-cryogenic anatomical imaging in ultra-low field regime: hand MRI demonstration. J Magn Reson. 2011;211(2):101-8.

51. Busch SE. Ultra-low field MRI of prostate cancer using SQUID detection. Berkeley: University of California; 2011.

52. Lips O, Privalov AF, Dvinskikh SV, Fujara F. Magnet design with high Bo homogeneity for fast-field cycling NMR applications. J Magn Reson. 2001; 149:22-8

53. Morgan PN, Conolly SM, Macovski A. A readout magnet for prepolarized MRI. Magn Reson Med. 1996;36:527-36.

54. Bidinosti CP, Choukeife J, Nacher P-J, Tastevin G. In vivo NMR of hyperpolarized $3 \mathrm{He}$ in human lung at very low magnetic fields. J Magn Reson. 2003:162:122-32.

55. Sousa DM, Marques GD, Sebastiao PT, Ribeiro AC. Design of nuclear magnetic resonance fast field cycling air cored magnet. In: PEDS; 2007.

56. Hilschenz I, Ito Y, Natsukawa H, Oida T, Yamamoto T, Kobayashi T. Remoted detected low-field MRI using an optically pumped atomic magnetometer combined with a liquid cooled pre-polarization coil. J Magn Reason. 2016: 274:89-94.

57. Lother S, Schiff S, Neuberger T, Jakob PM, Fidler F. Design of a mobile, homogeneous, and efficient electromagnet with a large field of view for neonatal low-field MRI. MAGMA. 2016:29(4):691-8.

58. Obungoloch J. Developing of ultra low field magnetic resonance imaging for diagnosis of hydrocephalus in developing countries; 2017.

59. Bejan A. Constructal-theory network of conducting paths for cooling a heat generating volume. Int J Heat Mass Transfer. 1997:40(4):799-816.

60. Lurie DJ. Field-cycled magnetic resonance imaging - techniques and applications. In: Field-Cycling NMR Relaxometry Symposium. Berlin: IOP Publishing; 1998. 
61. Gilbert KM, Handler WB, Chronik BA. Thermal modeling of resistive magnets for filed-cycled MRI. Concepts Magn Reson Part B (Magn Reson Eng). 2005: 26B(1):56-66.

62. Gilbert KM, Handler WB, Scholl TJ, Chronik BA. Modeling and evaluation of resistive magnet thermal performance in field-cycled MRI. In: International Society of Magnetic Resonance Medicine; 2007.

63. Sousa D, Fernandes P, Marques G, Ribeiro A, Sebastiao P. Novel pulsed switched power supply for a fast field cycling NMR spectrometer. Solid State Nucl Magn Reson. 2004;25:160-6.

64. Kosky P, Balmer R, Keaat W, Wise G. Chapter 12 - mechanical engineering. In: Exploring engineering; an introduction to engineering and design. Burlington: Elsevier Inc;; 2013. p. 259-81.

65. Lee-Whiting G. Uniform magnetic fields. Chalk River: Atomic Energy of Canada, Ltd; 1957.

66. Merritt RC, Purcell C, Stroink G. Uniform magnetic field produced by three, four, and five square coils. Rev Sci Instrum. 1983;54:879.

\section{Publisher's Note}

Springer Nature remains neutral with regard to jurisdictional claims in published maps and institutional affiliations.

Ready to submit your research? Choose BMC and benefit from:

- fast, convenient online submission

- thorough peer review by experienced researchers in your field

- rapid publication on acceptance

- support for research data, including large and complex data types

- gold Open Access which fosters wider collaboration and increased citations

- maximum visibility for your research: over $100 \mathrm{M}$ website views per year

At BMC, research is always in progress.

Learn more biomedcentral.com/submissions 